\title{
The Driving Force for Lath and Plate Martensite and the Activation Energy for Isothermal Martensite in Ferrous Alloys
}

\author{
A. Borgenstam and M. Hillert \\ Division of Physical Metallurgy, Department Materials Science and Engineering, KTH, \\ 10044 Stockholm, Sweden
}

\begin{abstract}
From information on $\mathrm{M}_{s}$ for lath and lenticular martensite the driving force for the start of a formation of the two types of martensite was calculated in a number of $\mathrm{Fe}-\mathrm{X}$ systems. By plotting the calculated driving force against temperature the results indicate that the driving force for formation of martensite may not be much affected by solution hardening but mainly be a function of temperature. From the kinetics of isothermal $\alpha$ martensite in ferrous alloys one can clearly distinguish between two groups of alloys, high alloy steels and carbon containing steels. High alloy steels with low $\mathrm{M}_{\mathrm{s}}$ temperature have a temperature dependence corresponding to a very low activation energy, possibly $7 \mathrm{~kJ} / \mathrm{mol}$. It can hardly depend on any diffusion process. Carbon containing steels have a temperature dependence corresponding to an activation energy of about $80 \mathrm{~kJ} / \mathrm{mol}$. Its rate of formation can be explained by assuming that it is triggered by submicroscopic plates of bainite formed with a rate of carbon diffusion.
\end{abstract}

\section{INTRODUCTION}

The progress of the understanding of the martensitic transformation in Fe-base alloys has been slow over the last few decades. Recently an attempt has been made to take a fresh look at the wealth of information available and to bring some order into this confusing field. The present report will be mainly focused on two recent publications [1,2]. In order to understand the mechanism of the fcc $\rightarrow$ bcc martensitic transformation in Fe alloys it is essential to know its driving force and how it varies with the alloy content and temperature. In order to evaluate the driving force it is necessary to know where martensite forms, in particular the $\mathrm{M}_{\mathrm{S}}$ line, and how the thermodynamic properties vary with temperature. Almost 30 years ago [3] there were indications of two separate $M_{s}$ lines in some Fe-X systems and later studies have produced more information of the same kind. Supposedly, one $\mathrm{M}_{\mathrm{S}}$ line concerns lath martensite and the other one plate martensite. However, with a few exceptions [4-7] most evaluations of the driving force are still based on a single $\mathrm{M}_{\mathrm{S}}$ line.

In the present work the existence of two $M_{S}$ lines was accepted and they were evaluated from experimental information on the martensitic plateaux, i.e. constant $\mathbf{M}_{\mathbf{S}}$ values in some range of cooling rates, observed in very rapid quenching experiments. In the present work an attempt to rationalise the resulting values of the driving force for several alloying elements was made by plotting the values as function of the temperature in a common diagram.

It is also interesting to examine the effect of alloying elements on isothermal $\alpha$ martensite in an attempt to identify the main mechanism of that phenomenon. The interest in the kinetics of the isothermal martensite formation has mainly centred around the shape of the isothermal transformation curve and to explain its sigmoidal shape. Many such models have been developed which is in contrast to the relatively few attempts to explain the shape of the C-curve which was the subject of the present work.

\section{TWO TYPES OF THE MARTENSITIC TRANSFORMATION,$\gamma \rightarrow \alpha$}

In 1971 Morozov et al. [8] studied the transformations in Fe with $0.01 \% \mathrm{C}$ from low to very high cooling rates. When plotting the arrest temperatures versus the cooling rate they found four plateaux and denoted them I, II, III and IV. They identified plateau III with the formation of martensite by slip (lath martensite) and plateau IV with the formation of martensite by twinning (plate martensite). When trying to draw curves for the two $\mathrm{M}_{\mathrm{s}}$ temperatures for various alloying elements in an attempt to evaluate the driving forces, we 
have mainly relied on information from plateaux obtained in very rapid cooling experiments. When such data are missing classical information on $\mathbf{M}_{\mathrm{S}}$ was used.

From a large amount of data two $\mathrm{M}_{\mathrm{S}}$ lines denoted $\mathrm{T}_{\mathrm{III}}$ and $\mathrm{T}_{\mathrm{TV}}$ have been drawn for $\mathrm{Fe}$ with $\mathrm{C}, \mathrm{Ni}, \mathrm{Cr}$, $\mathrm{Cu}, \mathrm{Co}$ or $\mathrm{Mn}$. The lines for Fe-C are shown in Fig. 1. It is evident that the information is not always good enough to determine the intersection of the two $M_{S}$ lines very accurately. The constructions of all the systems are therefore based on the choice of a common temperature of intersection, $250^{\circ} \mathrm{C}$. Diagrams for most other Fe-X systems are similar to Fig. 1. Fe-Co is an exception because Co increases the $\mathrm{M}_{\mathrm{S}}$ temperature. See Fig. 2.

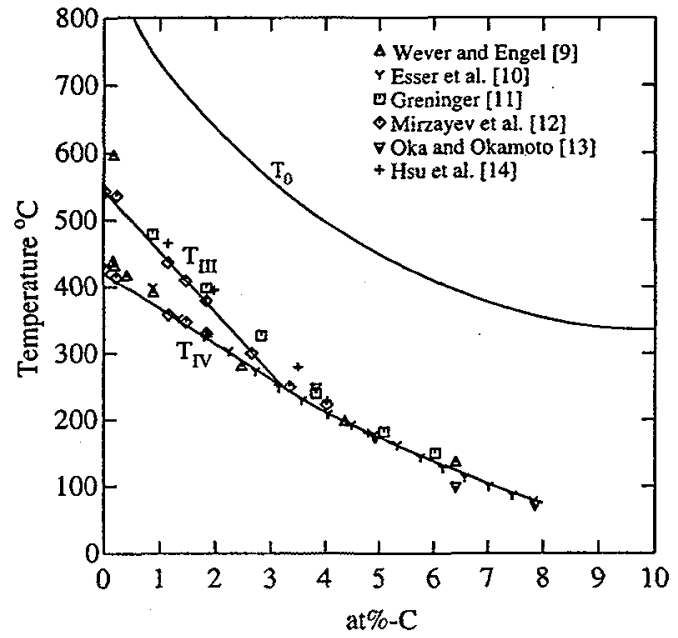

Fig. 1: Two $\mathrm{M}_{s}$ lines for $\gamma \rightarrow \alpha$ martensite in Fe-C.

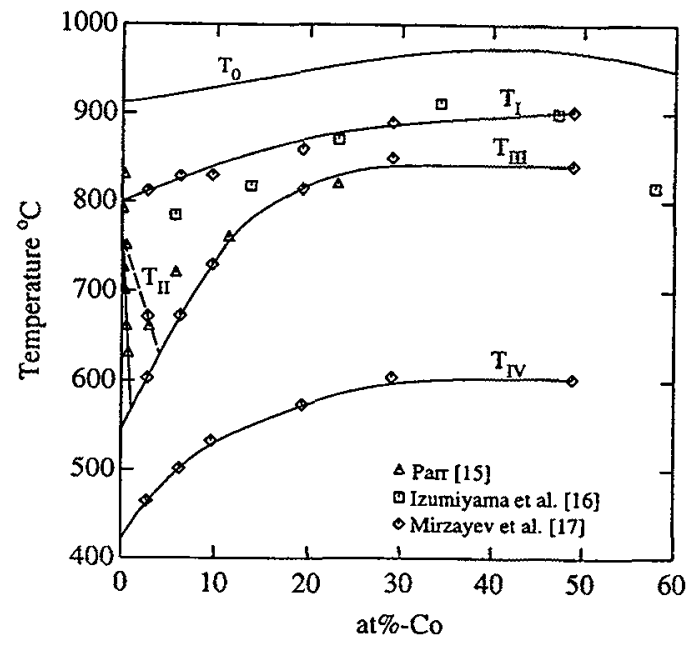

Fig. 2: Two $\mathrm{M}_{s}$ lines for $\gamma \rightarrow \alpha$ martensite in Fe-Co.

Information from all the systems is presented in Fig. 3 as $T_{m}-T_{r v}$ plotted versus $\left(T_{m}+T_{r v}\right) / 2$. This diagram gives a strong correlation between these two quantities. Of course, it should be realised that the good agreement for $\mathrm{C}, \mathrm{Mn}, \mathrm{Ni}$ and $\mathrm{Cu}$ mainly depends on the choice of a common temperature of intersection between the two $M_{S}$ lines. However, it is very interesting that the line for Co has almost the same slope although it goes to higher temperatures. The value of $T_{\mathrm{III}}-\mathrm{T}_{\mathrm{IV}}$ is closely related to the difference in driving force for the start of martensite transformation according to the two modes. Fig. 3 thus seems to indicate that this difference is mainly a function of temperature, here given as $\left(T_{\mathrm{II}}+T_{\mathrm{N}}\right) / 2$.

\section{VARIATION OF DRIVING FORCE WITH TEMPERATURE}

In view of the strong correlation between temperature and the difference in driving force for plate and lath martensite, indicated by Fig. 3, the driving forces, calculated from the SGTE solution database [18], at the plateau temperature for various alloying elements were plotted versus temperature in Fig. 4 . For each kind of martensite all the lines start from a point representing pure $\mathrm{Fe}$. It falls at $545^{\circ} \mathrm{C}$ for lath martensite and the effect of $\mathrm{Co}$ is described by an almost straight line up to $800^{\circ} \mathrm{C}$. The other elements decrease the $\mathrm{M}_{S}$ temperature and the general tendency is that they increase the driving force. It should be emphasised that there is a strong uncertainty in these values due to the uncertain thermodynamic descriptions. Anyway, accepting the lines for $\mathrm{C}$ and $\mathrm{Mn}$ as typical, it would be almost possible to describe the effect of temperature with a single straight line from 800 to $250^{\circ} \mathrm{C}$ for all alloying elements. See sloping dashed line in Fig. 4. That line would show that the driving force needed for starting the formation of lath martensite, increases strongly as the temperature is lowered. The dashed lines for lath martensite in Fig. 4 may be within the experimental uncertainty for most of the information. 


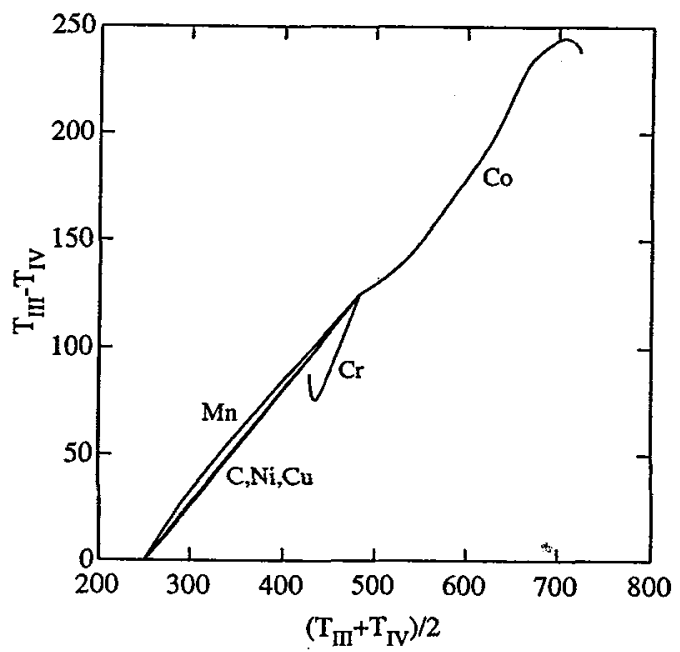

Fig. 3: The difference between the two $M_{S}$ temperatures as function of their mean value.

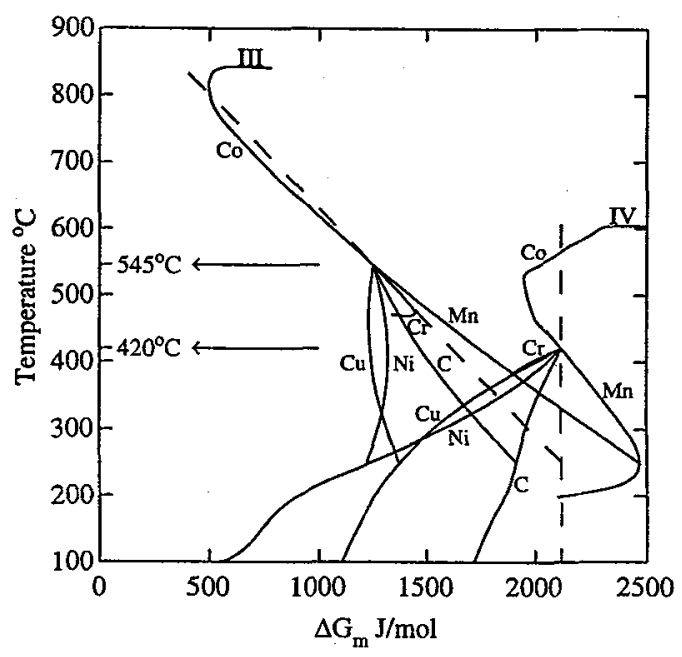

Fig. 4: The driving force for formation for martensite as a function of the $M_{S}$ temperature.

For plate martensite the effect of Co is much weaker and varies with temperature. It is difficult to draw a corresponding line representing all alloying elements. Accepting the sloping dashed line in Fig. 4 for lath martensite and $250^{\circ} \mathrm{C}$ as the intersection between the two $\mathrm{M}_{\mathrm{s}}$ lines, one can draw the line through that point of intersection and the point for pure Fe. The resulting line is almost vertical. Despite all uncertainties it is evident that the driving force for plate martensite varies with temperature much less than for lath martensite.

Accepting that there should be some line in Fig. 4 representing the effect of temperature on lath martensite, one should expect then to add a positive effect of solution hardening for each alloying element as one moves away from the value for pure $\mathrm{Fe}$ at $545^{\circ} \mathrm{C}$. This would make the line for Co steeper than the dashed line and for all the other elements the lines would be more horizontal. Such a difference between the lines for $\mathrm{Co}$, on one hand, and the other elements on the other is not shown by Fig. 4. It is difficult to avoid concluding that the effect of solution hardening is too weak to be noticed and that the main effect is caused by the temperature. This is contrary to the prevailing idea about the effect of alloying elements that they cause solution hardening and, thus, an increase of the driving force.

\section{ISOTHERMAL MARTENSITE IN HIGH ALLOY STEELS}

It is difficult to identify the start of the isothermal transformation if it is preceded by the formation of some athermal martensite. The present work was thus concentrated on the information on isothermal martensite above the $\mathbf{M}_{\mathbf{S}}$ temperature. High alloy steels with $\mathbf{M}_{\mathbf{S}}$ below room temperature were first considered. It is generally assumed that the kinetics of isothermal martensite is governed by the rate of nucleation because the observed rate of growth is very high. It is thus common to employ nucleation theory.

A completely different approach to the kinetics of isothermal martensite was attempted based on the experimental C-curve. It was assumed that the time it takes for a nucleus of martensite to develop is governed by an activated process that, in principle, could go forth and back and the net rate is given by the difference in rate, as in the absolute reaction rate theory [19]. If the driving force, $\mathrm{F}$, is small relative to the activation barrier, $\mathrm{Q}$, then one gets, $\mathrm{v} \cong \mathrm{k} \cdot(\mathrm{F} / \mathrm{RT}) \cdot \exp (-\mathrm{Q} / \mathrm{RT})$.

In principle, it should be easy to evaluate $F$ as a function of temperature. However, the thermodynamic descriptions of the iron-base systems are not very reliable at low temperatures. It was simply assumed that $F$ is proportional to $T_{0}-T$, where $F$ was assumed to start from zero at $T_{0}$, the temperature where the time of formation of isothermal martensite goes to infinity, i.e. $\mathbf{M}_{\mathbf{s i}}$. The constant of proportionality is equal to the negative of the entropy of transformation. Thus, $\mathrm{F} / \mathrm{T}$ was assumed to be proportional to $\left(\mathrm{M}_{\mathrm{si}} / \mathrm{T}-1\right)$ which gives $v=1 / t \cong k / R \cdot\left(M_{s i} / T-1\right) \cdot \exp (-Q / R T)$, where $t$ is the time of formation of a certain low fraction of isothermal martensite and $k$ is a constant of proportionality. The quantity $t \cdot\left(M_{s i} / T-1\right)$ was thus plotted logarithmically versus $-1 / T$ in an attempt to extract the activation energy, $Q$.

The information on the C-curves in Fe-Ni-Mn was thus modified by multiplying the time with $\left(\mathrm{M}_{\mathrm{si}} / \mathrm{T}\right.$ 1) and plotting it logarithmically versus - $1 / \mathrm{T}$. See Figs. 5 and $6 . \mathrm{M}_{\mathrm{Si}}$ was chosen as the highest reported 
temperature for isothermal transformation to martensite in each alloy since it has not been determined experimentally in the various alloys. The information on $\mathrm{Fe}-\mathrm{Cr}-\mathrm{Ni}$ was treated in the same way. A straight line was then chosen to fit the data for both $\mathrm{Fe}-\mathrm{Ni}-\mathrm{Mn}$ and $\mathrm{Fe}-\mathrm{Cr}-\mathrm{Ni}$. The value of $\mathrm{M}_{\mathrm{si}}$ was then changed so that the point at the highest temperature of each experimental curve falls on the chosen line. At lower temperatures the straight line gives a strong indication: that the rate controlling mechanism at low temperatures is essentially the same for all these steels and its temperature dependence can be evaluated from the straight line. It yields the surprisingly low activation energy of about $7 \mathrm{~kJ} / \mathrm{mol}$. The rate limiting mechanism thus seems to be a process with a very low activation energy. It can hardly be a process involving individual movements of atoms. It would seem more promising to compare with the activation energy for slip or twinning although it may be difficult to see how such processes can take such a long time. At higher temperatures the fit of data to the straight line is less convincing and it cannot be used to support the kinetic equation. However, that was not the main purpose.

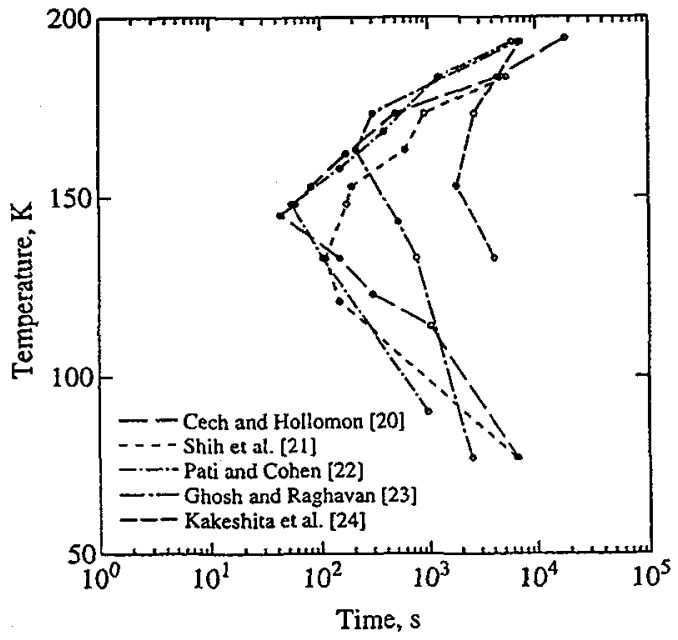

Fig. 5: Isothermal formation of martensite in $\mathrm{Fe}-\mathrm{Ni}-\mathrm{Mn}$ alloys with very low $\mathrm{M}_{\mathrm{S}}$.

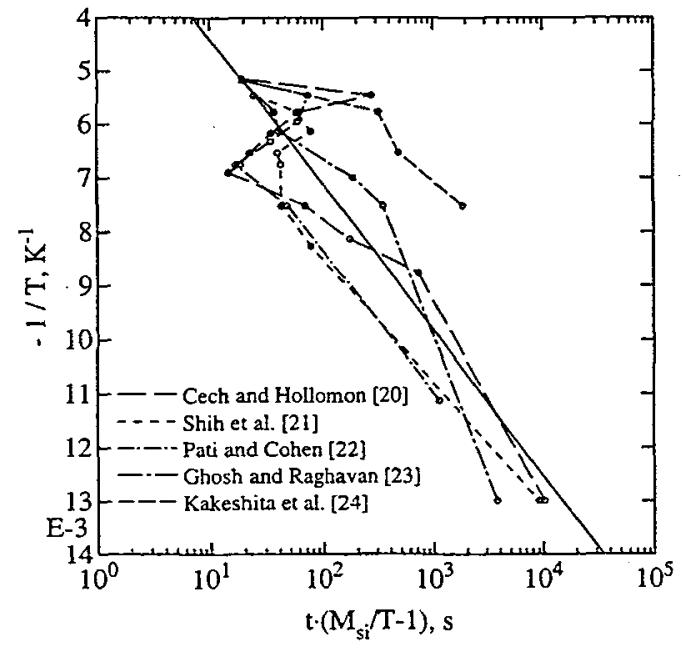

Fig. 6: Information from Fig. 5, replotted in order to evaluate the low temperature asymptote.

\section{ISOTHERMAL MARTENSITE IN FE-C ALLOYS AND PLAIN CARBON STEELS}

In the $\mathrm{Fe}-\mathrm{C}$ alloys and plain carbon steels isothermal martensite has been observed above room temperature and close to lower bainite. The kinetics of lower bainite was first examined as a background for the analysis of the kinetics of isothermal martensite. It was assumed that the edgewise growth rate of bainite, including lower bainite, is mainly governed by diffusion of carbon away from the edge of a growing ferrite plate. In order to compare TTT diagrams for different steels it was thus convenient first to eliminate the effect of the carbon content. This may be done by applying Hillert's modification of Zener's equation for lengthening of a plate [25], which yields

$\mathrm{v}=\frac{\mathrm{D}}{\mathrm{r}} \cdot \frac{\Delta \mathrm{x}^{\text {matrix }}}{\Delta \mathrm{x}^{\text {transf }}} \cong \frac{\mathrm{D}\left(\mathrm{x}^{\gamma / \alpha}-\mathrm{x}^{\mathrm{o}}\right)^{2}}{\mathrm{x}^{\mathrm{o}}} \cdot \frac{\mathrm{RT}}{8 \sigma \mathrm{V}_{\mathrm{m}}}$

$\mathrm{x}^{0}$ is the initial mole fraction of carbon in the steel. The diffusion coefficient $\mathrm{D}$ varies with temperature and with $\mathrm{x}$. In order to reduce the uncertainty in a comparison between different steels one may thus study not the rate $\mathrm{v}$ directly but $\mathrm{vx} / \mathrm{T}$ which was then interpreted roughly as $\mathrm{D} \cdot\left(\mathrm{x}^{\gamma / \alpha}-\mathrm{x}^{\mathrm{O}}\right) \mathrm{R} / 8 \sigma \mathrm{V} \mathrm{m}$. It will be assumed that the time to form a certain low fraction is proportional to the lengthening rate, and $\log \left[\mathrm{t} \cdot \mathrm{T} / \mathrm{x}^{0}\right]$ was thus plotted against $-1 / T$. Information for formation of bainite was taken from a number of careful studies of TTT diagrams for low and high alloy steels and a single low temperature asymptote could be filled reasonably well to all the curves, see information from $\mathrm{Cr}$ steels in Fig. 7. Its slope corresponds to an activation energy of $80 \mathrm{~kJ} / \mathrm{mol}$. 


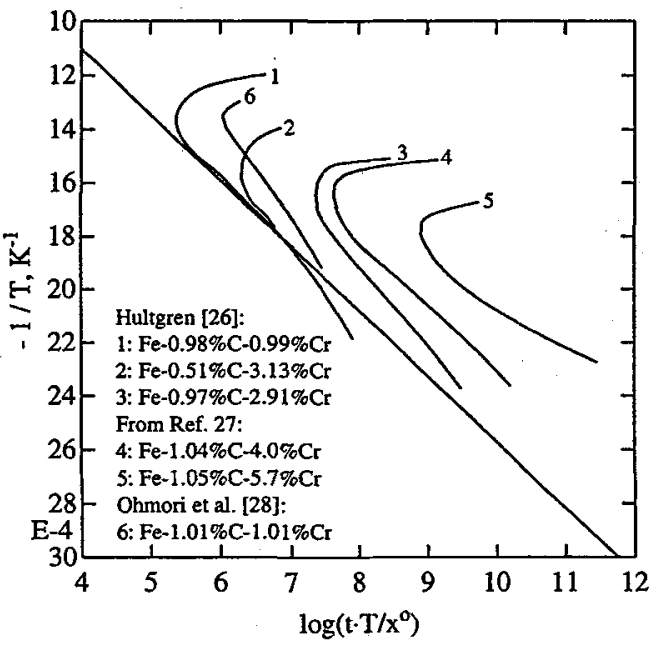

Fig. 7: Information on isothermal formation of lower bainite in $\mathrm{Cr}$ steels.

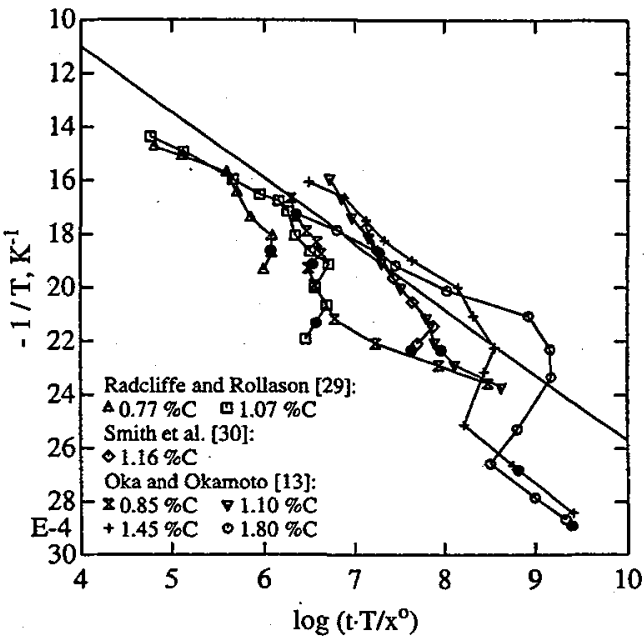

Fig. 8: Information on isothermal formation of martensite and lower bainite in $\mathrm{Fe}-\mathrm{C}$ alloys. The information falling below the asymptote concerns isothermal martensite.

The information on steels transforming to bainite as well as isothermal martensite was treated in the same way, see information from Fe-C alloys in Fig. 8, where the same asymptote was included. It is striking that the data on isothermal martensite is related to the data on lower bainite but displaced to shorter times by a factor of about 10 .

It may be suggested that the formation of isothermal martensite in these alloys is closely related to the formation of lower bainite, e.g. by the following mechanism. Suppose the C-curves for bainite represents the formation of bainite units of a detectable size, say $10 \mu \mathrm{m}$ in length. Assuming constant growth rate and a negligible incubation time one can then estimate that the bainite units were about $0.1 \mu \mathrm{m}$ at the time when isothermal martensite starts to form. It thus seems possible that the isothermal formation of martensite units in these alloys may have been triggered by bainite units when they reached a size of about $0.1 \mu \mathrm{m}$. The slope of the straight line can be explained by assuming that the rate of formation of bainite is governed by diffusion of carbon away from the advancing edge of an $\alpha$ plate.

\section{CONCLUSIONS}

Two different $\mathrm{M}_{\mathrm{S}}$ lines for lath and plate martensite are here accepted. It is possible to account for most of the experimental information on the effect of $\mathrm{C}, \mathrm{Mn}, \mathrm{Ni}$ and $\mathrm{Cu}$ as alloying elements to $\mathrm{Fe}$ by accepting that the temperature of intersection is $250^{\circ} \mathrm{C}$ for all of them.

The calculation of the driving force for the start of martensite formation is rather uncertain due to uncertainties in the thermodynamic descriptions of the binary Fe-X systems at low temperatures and high alloy contents. However, the results on lath martensite indicate that the dependence of the driving force on the alloy content is mainly an effect of temperature and less an effect of solution hardening. The driving force increases, approximately linearly from $500 \mathrm{~J} / \mathrm{mol}$ at $800^{\circ} \mathrm{C}$ to $2100 \mathrm{~J} / \mathrm{mol}$ at $250^{\circ} \mathrm{C}$. It should be emphasised that this result depends on the choice of $250^{\circ} \mathrm{C}$ as the temperature of intersection between the two $M_{S}$ lines. In view of the considerable uncertainties involved, the result should be regarded as an interesting possibility rather than a proved fact. For plate martensite the driving force is rather independent of temperature and alloy content, about $2100 \mathrm{~J} / \mathrm{mol}$. The conclusion is that the main barriers for formation of martensite are present already in pure Fe. They may be connected to the structure of the interface or to the mechanism of deformation. It is known that twinning plays an important role for plate martensite and slip for lath martensite. A very simple and probably too naïve suggestion of the difference in behaviour of the driving force for the two kinds of martensite would be that the driving force for twinning is high but relatively independent of temperature and the driving force for slip is lower at high temperatures but increases drastically at lower temperatures.

In the analysis of isothermal martensite many details were neglected but it seems possible to identify general tendencies. The main result of the present work is the conclusion that the information on isothermal 
martensite actually concerns different phenomena in two different types of steels. It should here br emphasised that only so called $\alpha$ martensite was examined.

For high alloy steels with low $\mathrm{M}_{\mathrm{S}}$ the slope of the low temperature asymptote corresponds to at activation energy of $7 \mathrm{~kJ} / \mathrm{mol}$. Even though this value is very uncertain, the analysis clearly indicates tha the rate controlling mechanism has: a very low activation energy and can hardly depend on any diffusior process. It is more probable that dislocation movements are involved.

In carbon containing steels, which also transform to bainite, the time of formation of isotherma martensite is about one tenth of the time for the first observation of lower bainite. It thus seems natural to propose that isothermal martensite in these alloys is triggered by the formation of submicroscopic plate-liki bainite, still too small to be recognised as bainite. The slope of the asymptote corresponds to an activatior energy of about $80 \mathrm{~kJ} / \mathrm{mol}$. This is very much higher than the value obtained for the first group of alloys anc from a practical point of view it is not difficult to distinguish between the two cases.

\section{Acknowledgements}

This work was supported by a special grant from the Royal Institute of Technology and NUTEK. Thank: are also due to professor John Ågren for his advice and encouragement.

\section{References}

[1] Borgenstam A. and Hillert M., Acta Mater. (1997)

[2] Borgenstam A. and Hillert M., Acta Mater. 45 (1997) 651-662

[3] Wilson E.A., PhD thesis (University of Liverpool 1965)

[4] Shteynberg M.M., Mirzayev D.A. and Ponomareva T.N., Phys. Met. Metall. 43 (1977) 143-149.

[5] Wilson E.A., Met. Sci. 18 (1984) 471-484.

[6] Mirzayev D.A., Schastlivtsev V.M. and Tayzetdinova A.G., Phys. Met. Metall. 63 (1987) 99-105.

[7] Zhao J, and Jin Z., Acta Metall. Mat. 38 (1990) 425-431.

[8] Morozov O.P., Mirzayev D.A. and Shteynberg M.M., Phys. Met. Metal. 32 (1971) 170-177.

[9] Wever F. and Engel N., Mitt. K.-W. Inst. Eisenf. 12 (1930) 93-114.

[10] Esser H., Eilender W. and Spenle E., Archiv Eisenh. 6 (1933) 389-393.

[11] Greninger A.B., Trans. ASM 30 (1942) 1-26.

[12] Mirzayev D.A., Steynberg M.M., Ponomareva T.N. and Schastlivtsev V.M., Phys. Met. Metall. 47 (1979) 102-111.

[13] Oka M. and Okamoto H., Metall. Trans. 19A (1988) 447-452.

[14] Hsu T.Y., Zhang H. and Luo S., Acta. Metall. Sin. 20 (1984) A151-A161.

[15] Gordon Parr J., J. Iron Steel Inst. 205 (1967) 426-427.

[16] Izumiyama M., Tsuchiya M. and Imai Y., Sci. Rep. Res. Inst. Tohoku Univ. 22A (1970) 105-115.

[17] Mirzayev D.A., Shteynberg M.M., Ponomareva T.N., Byl'skiy B.Ya. and Karzunov S.Ye., Phys Met. Metall. 51 (1981) 116-127.

[18] SGTE solution database with Thermo-Calc extensions, Dept. of Materials Science and Engineering, Royal Institute of Technology, Stockholm, Sweden

[19] Glasstone S., Laidler K.J. and Eyring H., The theory of rate processes (McGraw-Hill, New York, 1941)

[20] Cech R.E. and Hollomon J.H., Trans. AIME, J. Metals 197 (1953) 685-689.

[21] Shih C.H., Averbach B.L. and Cohen M., Trans. AIME, J. Metals 203 (1955) 183-187.

[22] Pati S.R. and Cohen M., Acta Metall. 19 (1971) 1327-1332.

[23] Ghosh G. and Raghavan V., Mat. Sci. Eng. 80 (1986) 65-74.

[24] Kakeshita T., Kuroiwa K., Shimizu K., Ikeda T., Yamagishi A. and Date M., Mater. Trans. JIM 34 (1993) 415-422.

[25] Hillert M., Metall. Mater. Trans. 25A (1994) 1957-1966.

[26] Hultgren A., Jernkontorets Annaler 135 (1951) 403-494.

[27] Supplement to the Atlas of Isothermal Transformation Diagrams (United States steel Corporation, Pittsburgh, PA, 1953)

[28] Ohmori Y., Ohtsubo H., Georgima K., Maruyama N., Mater. Trans. JIM 34 (1993) 216-223.

[29] Radcliffe S.V. and Rollason E.C., J. Iron Steel Inst. 191 (1959) 56-65.

[30] Smith M.F., Speich G.R. and Cohen M., Trans. AIME 215 (1959) 528-530. 